This article is licensed under the Creative Commons Attribution-NonCommercial 4.0 International License (CC BY-NC) (http://www.karger.com/Services/OpenAccessLicense). Usage and distribution for commercial purposes requires written permission.

\title{
Cystoid Macular Edema during Treatment with Paclitaxel and Bevacizumab in a Patient with Metastatic Breast Cancer: A Case Report and Literature Review
}

\author{
Takamichi Yokoe $^{a, b}$ Ippei Fukadab ${ }^{\text {Kokoro Kobayashib }}$ \\ Tomoko Shibayamab $^{b}$ Yumi Miyagi $^{\mathrm{a}}$ Atsushi Yoshida ${ }^{c}$ Takuji Iwase $^{\mathrm{a}}$ \\ Shinji Ohno ${ }^{a, b}$ Yoshinori Ito ${ }^{b}$ \\ ${ }^{a}$ Department of Breast Surgical Oncology, The Cancer Institute Hospital of Japanese

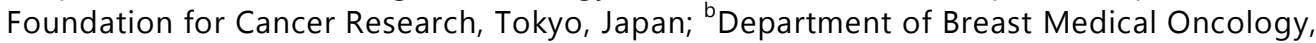 \\ The Cancer Institute Hospital of Japanese Foundation for Cancer Research, Tokyo, Japan; \\ 'Department of Ophthalmology, The Cancer Institute Hospital of Japanese Foundation for \\ Cancer Research, Tokyo, Japan
}

\section{Keywords}

Cystoid macular edema · Macular edema - Optical coherence tomography · Paclitaxel · Bevacizumab $\cdot$ Breast cancer

\section{Abstract}

We present a case of a metastatic breast cancer patient with cystoid macular edema (CME) occurring during treatment with paclitaxel and bevacizumab. She had a history of neoadjuvant chemotherapy and partial mastectomy plus axillary lymph node dissection for stage IIB left-breast cancer. Twenty-four months later, she was diagnosed with multiple bone metastases and underwent chemotherapy with paclitaxel and bevacizumab. Thirty-three months after 


\section{Case Reports in Oncology}

Case Rep Oncol 2017;10:605-612

DOI: $10.1159 / 000477897$

(C) 2017 The Author(s). Published by S. Karger AG, Basel www.karger.com/cro

Yokoe et al.: Cystoid Macular Edema during Treatment with Paclitaxel and Bevacizumab in a Patient with Metastatic Breast Cancer: A Case Report and Literature Review

the initiation of the chemotherapy, she noticed bilateral blurred vision. The retinal thickening with macular edema was observed by optical coherence tomography, resulting in a diagnosis of CME. With cessation of paclitaxel and administrating ocular instillation of a nonsteroidal anti-inflammatory drug, her macular edema gradually reduced and disappeared in a month. While CME caused by chemotherapy is very rare, taxane may cause ocular adverse events such as CME. It is important to urge patients to consult an ophthalmologist promptly when they have visual complaints during taxane chemotherapy.

(C) 2017 The Author(s)

Published by S. Karger AG, Basel

\section{Introduction}

Paclitaxel is an anticancer agent classified as a taxane drug used for various types of solid malignant tumors, playing a key role in breast cancer treatment. Paclitaxel acts on microtubule mobility and inhibits mitosis. Adverse events such as myelosuppression, peripheral neuropathy, allergic reaction, arthralgia, and depilation are commonly seen in patients undergoing paclitaxel therapy. Ophthalmic adverse events can include visual loss due to optic neuropathy and cystoid macular edema (CME) $[1,2]$. However, CME is thought to be a very rare adverse event since there has been no report about a case series of CME due to chemotherapy. There are several reports of taxane-related CME. Bevacizumab may reduce the degree of drug-induced CME. A few papers, however, reported CME induced by taxane with bevacizumab. We report a case of CME that occurred during treatment with paclitaxel and bevacizumab.

\section{Case Report}

A 47-year-old female was diagnosed with invasive left-breast cancer at stage IIB. The hormone receptors were positive and HER2 was negative (IHC 1+). Ki67 of the labeling index was high. She received 4 cycles of FEC (fluorouracil $500 \mathrm{mg} / \mathrm{m}^{2}$, epirubicin $100 \mathrm{mg} / \mathrm{m}^{2}$, cyclophosphamide $500 \mathrm{mg} / \mathrm{m}^{2}$, day 1, every 3 weeks), followed by 12 cycles of weekly paclitaxel at a dose of $80 \mathrm{mg} / \mathrm{m}^{2}$. Neoadjuvant chemotherapy yielded partial response according to the response evaluation criteria in solid tumors (RECIST version 1.1). She underwent a partial mastectomy and axillary dissection at level II. The pathological finding showed residual invasive ductal carcinoma with surgical margin positive. Four out of 25 resected lymph nodes involved metastasis. She underwent postmastectomy radiation therapy and started hormonal therapy with tamoxifen. Two years after surgery, bone scintigraphy and positron emission tomography detected multiple bone metastases in her left 6th rib and thoracic vertebral bodies from the left 9th to 11th ribs. She was enrolled in a clinical trial (UMIN000009300), which evaluated efficacy and tolerance in maintenance treatment after paclitaxel plus bevacizumab. She received paclitaxel $90 \mathrm{mg} / \mathrm{m}^{2}$ on days 1, 8, and 15, and bevacizumab $10 \mathrm{mg} / \mathrm{kg}$ on days 1 and 15, every 4 weeks. She achieved partial durable response.

After 31 cycles of paclitaxel plus bevacizumab, she complained of blurred vision and consulted an ophthalmologist. Her best corrected visual acuity was 1.2 in both eyes, and intraocular pressure was normal. Optical coherence tomography (OCT) revealed CME in both eyes (Fig. 1). There were large cystic spaces in the outer layer and small cystic spaces in the inner nuclear layer of both eyes. Retinal thickness was increased in the center of the macula due to the edema.

We suspected that paclitaxel was the causing agent and decided that it should be stopped, and bevacizumab alone was continued. Three weeks later, following ocular instillation of a nonsteroidal anti- 


\section{Case Reports in Oncology}

Case Rep Oncol 2017;10:605-612

DOI: $10.1159 / 00047789$

(C) 2017 The Author(s). Published by S. Karger AG, Base www.karger.com/cro

Yokoe et al.: Cystoid Macular Edema during Treatment with Paclitaxel and Bevacizumab in a Patient with Metastatic Breast Cancer: A Case Report and Literature Review

inflammatory drug, bromfenac, the retinal thickness and cystic spaces decreased gradually on OCT scans (Fig. 2). Her blurred vision disappeared, and retinal thickness has been maintained in a normal state since that time.

\section{Discussion}

The present case showed bilateral CME during paclitaxel and bevacizumab treatment.

CME induced by taxane chemotherapy is rare, but there are several articles reporting this adverse event (Table 1). A case has been reported of CME in both eyes secondary to paclitaxel at a dose of $175 \mathrm{mg} / \mathrm{m}^{2}$ after 10 months of use without any evidence of fluorescein leakage [3]. The treatment was changed from paclitaxel to capecitabine, and 6 weeks after discontinuing paclitaxel the patient's visual symptoms recovered, and fundus examination and OCT scans revealed resolution of CME. Four cases of CME associated with docetaxel therapy were documented [4-6]. Two authors reported CME due to albumin-bound paclitaxel, with resolution on discontinuation of the drug $[7,8]$. In all these reports, the main complaint was decline in visual acuity.

CME is a condition characterized by abnormal thickening of the retina associated with excess fluid accumulation within the macular retina. The precise pathogenesis of CME remains unclear. It is thought to occur following disruption of the blood-retinal barrier. Furthermore, Müller cells play an important role in dehydrating the macula by metabolic pumps. These conditions are induced by either microvascular occlusion or inflammatory disease [2].

The typical fluorescein angiographic appearance of CME consists of small focal leaks early on that increase in size and intensity, resulting in late pooling in a characteristic flower petal pattern with or without leakage surrounding the optic nerve [4]. For drug-induced CME, several papers have reported that CME was not associated with leakage on fluorescein angiography $[3-5,7,9]$. Therefore, the mechanisms of drug-induced CME may be different from those of CME associated with microvascular occlusion or inflammatory disease.

The pathogenesis of CME without fluorescein leakage is unclear. A subcategory of CME not associated with leakage on fluorescein angiography and therefore abnormal capillary permeability has been described and is associated with toxicity to niacin [4].

Nicotinic acid maculopathy was first described by Gass [10] in 1973. He reported 3 patients with decreased visual acuity and visual symptoms who were taking nicotinic acid for hypercholesterolemia. All patients were found to have CME by indirect biomicroscopy, but no leakage or alteration in the capillary bed was noted upon fluorescein angiography. Visual acuity returned to normal in all 3 patients following discontinuation of the drug, but 1 of the patients still had residual CME 4 months after discontinuing the nicotinic acid. Millay et al. [11] have hypothesized that the blood-retina barrier was intact and that the cystic changes were secondary to disturbed metabolism of the inner retinal neurons with intracellular fluid accumulation. Jampol [12] has proposed 2 possibilities for the etiology of the cystic changes in niacin retinopathy. The first is subclinical leakage in the extracellular space, stimulated by the release of prostaglandins by niacin. The other possibility is toxicity to Müller cells with subsequent swelling that was not sufficient to disrupt the blood-retina barrier. 


\section{Case Reports in Oncology}

CME can be associated with many ocular conditions, including (1) microvascular occlusion such as diabetic macular disease, retinal vein occlusion, and retinal arteriolar macroaneurysm, (2) inflammatory disease such as uveitis, a condition following cataract surgery, and (3) other conditions such as retinitis pigmentosa and drug agents [2].

CME can also be caused by various drugs such as taxanes, thiazolizine, tamoxifen, niacin, interferon, fingolimod, prostaglandin, epinephrine, timolol, and others. In taxanes, paclitaxel is commonly reported $[1,9,13]$, followed by nanoparticle albumin-bound paclitaxel $[7,8]$ and docetaxel $[4-6,14]$.

In the case of the present patient, who had a history of medication with tamoxifen, it is possible that tamoxifen caused her CME. A common ocular adverse event of tamoxifen is bilateral yellow-white refractile crystalline deposits and pigmentary alterations in the macula. Macular edema and CME were reported in patients receiving high doses ( $>180 \mathrm{mg} /$ day) of tamoxifen. Toxicity is not common at the usual dose of 20-40 mg/day. Moreover, CME will disappear with discontinuation of tamoxifen [15]. Therefore, we concluded that a history of tamoxifen usage did not evoke CME.

The characteristics of drug-induced CME are (1) often bilateral, (2) no leakage of contrast agent in fluorescein angiography [14], (3) a larger cystic space in the outer layer rather than the inner layer of the retina in OCT scans [8], and (4) spontaneous resolution and improvement of visual acuity after discontinuation of the cause [9]. In some cases with delayed diagnosis of CME, progression of macular degeneration occurred, and then visual acuity could not be reversed [16].

Treatments for drug-induced CME are (1) cessation of the causing agent, (2) dorzolamide, (3) a nonsteroidal anti-inflammatory drug such as bromfenac sodium hydrate, (4) subTenon injection of triamcinolone acetonide, which is a synthetic long-acting corticosteroid, and (5) injection of an anti-VEGF agent. Stopping the drug thought to be causing the condition is the first choice for treating drug-induced CME. When this is not enough to cure CME, drug-induced CME is treated the same as CME induced by vascular or inflammatory diseases [2]. There is no clear evidence for a treatment specific to drug-induced CME other than removing the cause. Some adverse events of injection such as endophthalmitis, cataracts, increased ocular pressure, and floaters are reported, and continuous follow-up is needed after treatment $[2,14]$. Most taxane-related drug-induced CME was cured by discontinuation of the causing drugs only or by discontinuation plus ocular instillation of dorzolamide or acetazolamide.

In a case involving another antitumor agent, imatinib, CME associated with chronic myeloid leukemia and imatinib was treated with intravitreal injection of bevacizumab and triamcinolone [17]. Since injection of bevacizumab, an anti-VEGF agent, is used to treat CME, bevacizumab treatment for breast cancer might have reduced the degree of paclitaxelinduced CME. This issue should be investigated further as there is only 1 case report to support this idea [7].

We have presented a case of a patient with bilateral CME after receiving paclitaxel and bevacizumab. Complaining of blurred vision, the patient was diagnosed with drug-induced CME by paclitaxel. Following the cessation of paclitaxel and ocular instillation, CME was cured. Our observation confirmed that CME secondary to paclitaxel shows spontaneous resolution of visual complaint and macular edema by removing the causing agent [3]. 


\section{Case Reports in Oncology}

In daily clinical practice, oncologists should ask patients about visual complaints. It is important for those with visual complaints during chemotherapy to consult an ophthalmologist promptly because decreased visual acuity may be irreversible if treatment is delayed. Another important issue is that chemotherapy may need to be halted in patients who develop CME. In the present case, since the metastatic lesion was only in her bones and metastatic disease was stable, we did not hesitate to cease paclitaxel and convert the treatment to therapy with bevacizumab alone.

\section{Conclusion}

Chemotherapy with paclitaxel may cause CME. Further research is necessary to clarify the mechanisms of drug-induced CME. Attention to possible ocular adverse events of paclitaxel is needed to avoid serious ocular problems such as decreased visual acuity. Oncologists need to draw information regarding treatment-related visual complaints from patients, and both doctors and patients need to discuss with ophthalmologists the risks and benefits of continuing paclitaxel.

\section{Statement of Ethics}

The authors have no ethical conflicts to disclose.

\section{Disclosure Statement}

S. Ohno has received lecture fees from Chugai, Inc.; Y. Ito has received research funding fees from Chugai, Inc. No financial support was received for this submission. The authors have no financial or proprietary interest in any material or method mentioned. The material of this manuscript was not previously presented at a meeting.

\section{Author Contributions}

T.Y., I.F., K.K., Y.M., and A.Y. interacted with the patient. T.Y. and I.F. identified and acquired relevant reports. A.Y. diagnosed the patient by ophthalmological examination. T.Y. drafted the report. I.F., K.K., T.S., Y.M., A.Y., T.I., and S.O. critically reviewed the report. All authors read and approved the final submitted version. 


\section{Case Reports in Oncology}

Yokoe et al.: Cystoid Macular Edema during Treatment with Paclitaxel and Bevacizumab

in a Patient with Metastatic Breast Cancer: A Case Report and Literature Review

\section{References}

1 Hofstra LS, de Vries EG, Willemse PH: Ophthalmic toxicity following paclitaxel infusion. Ann Oncol 1997;8:1053.

Rotsos TG, Moschos MM: Cystoid macular edema. Clin Ophthalmol 2008;2:919-930.

Joshi MM, Garretson BR: Paclitaxel maculopathy. Arch Ophthalmol 2007;125:709-710.

Teitelbaum BA, Tresley DJ: Cystic maculopathy with normal capillary permeability secondary to docetaxel. Optom Vis Sci 2003;80:277-279.

5 Telander DG, Sarraf D: Cystoid macular edema with docetaxel chemotherapy and the fluid retention syndrome. Semin Ophthalmol 2007;22:151-153.

-6 Enzsoly A, Kammerer K, Nemeth J, Schneider M: Bilateral cystoid macular edema following docetaxel chemotherapy in a patient with retinitis pigmentosa: a case report. BMC Ophthalmol 2015;15:32. Murphy CG, Walsh JB, Hudis CA, Lake D, Theodoulou M: Cystoid macular edema secondary to nabpaclitaxel therapy. J Clin Oncol 2010;28:e684-e687. Smith SV, Benz MS, Brown DM: Cystoid macular edema secondary to albumin-bound paclitaxel therapy. Arch Ophthalmol 2008;126:1605-1606.

$\checkmark 9$ Kuznetcova TI, Cech P, Herbort CP: The mystery of angiographically silent macular oedema due to taxanes. Int Ophthalmol 2012;32:299-304.

10 Gass JD: Nicotinic acid maculopathy. Am J Ophthalmol 1973;76:500-510.

11 Millay RH, Klein ML, Illingworth DR: Niacin maculopathy. Ophthalmology 1988;95:930-936. Jampol LM: Niacin maculopathy. Ophthalmology 1988;95:1704-1705.

13 Ham DS, Lee JE, Kim HW, Yun ICH: A case of cystoid macular edema associated with Paclitaxel chemotherapy. Korean J Ophthalmol 2012;26:388-90.

14 Makri OE, Georgalas I, Georgakopoulos CD: Drug-induced macular edema. Drugs 2013;73:789-802. Nayfield SG, Gorin MB: Tamoxifen-associated eye disease. A review. J Clin Oncol 1996;14:1018-1026. Matsuoka N, Hasebe H, Mayama T, Fukuchi T: Sub-Tenon injections of triamcinolone acetonide had limited effect on cystoid macular edema secondary to nanoparticle albumin-bound-paclitaxel (Abraxane). Case Rep Ophthalmol Med 2015;2015:181269.

17 Newcott EK, Ellabban AA, Tavassoli S, Sallam A: Intravitreal bevacizumab and triamcinolone for treatment of cystoid macular oedema associated with chronic myeloid leukaemia and imatinib therapy. Case Rep Ophthalmol Med 2015;2015:713868.
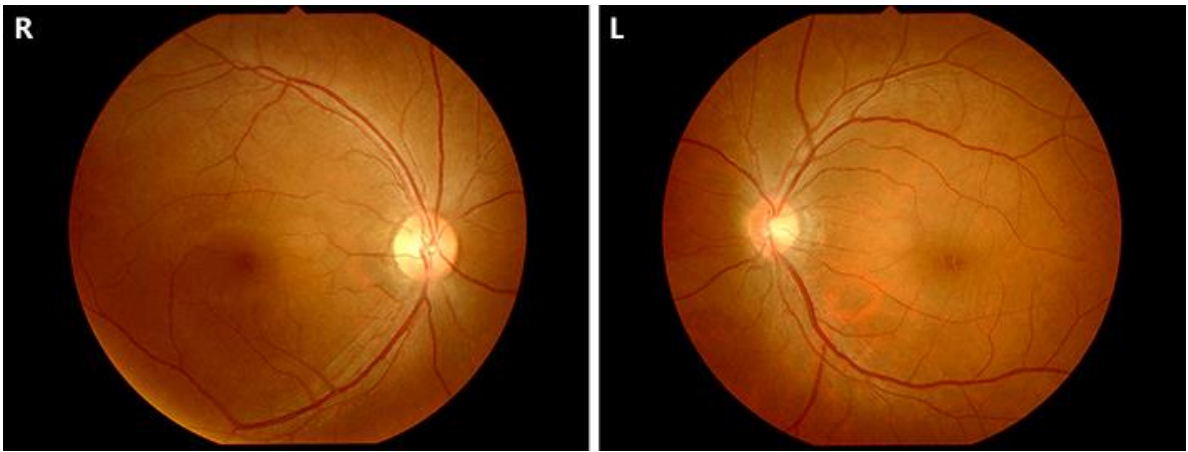

Fig. 1. Ophthalmoscopy. Macular edema at the fovea is seen in both eyes. 


\section{Case Reports in Oncology}
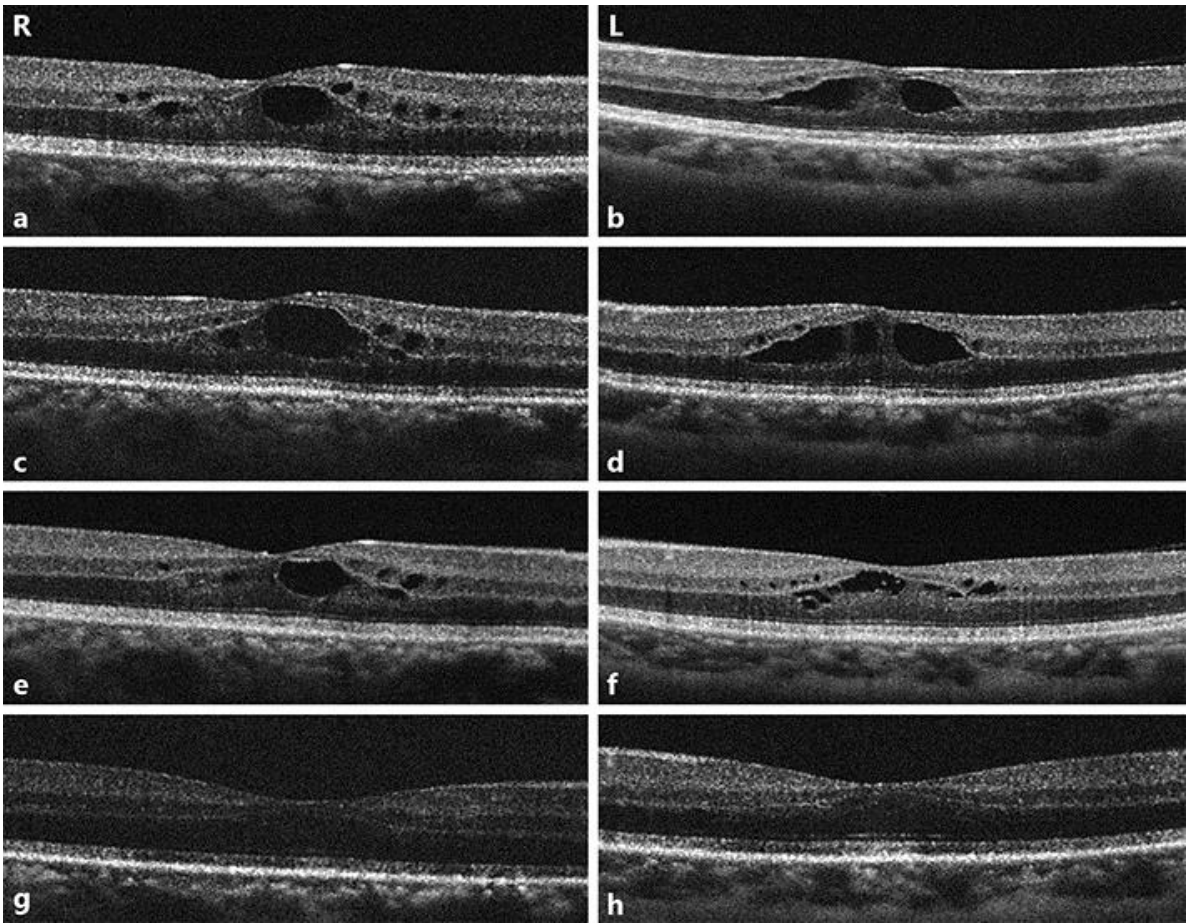

Fig. 2. a-h Optical coherence tomography (OCT) scans of the macula densa of both eyes in time course. a, b OCT scans at diagnosis. Large cystic spaces are seen in the outer reticular layer and small cystic spaces in the inner nuclear layer. Retinal thickness is lower outside the perifoveal area. c, d OCT scans at 1 week following diagnosis, when paclitaxel was ceased. e, $\mathbf{f}$ One week after cessation of paclitaxel. $\mathbf{g}$, $\mathbf{h}$ Three weeks after cessation of paclitaxel. Cystic spaces and retinal thickness gradually decreased. 


\section{Case Reports in Oncology}

Yokoe et al: Cystoid Macular Edema during Treatment with Paclitaxel and Bevacizumab in a Patient with Metastatic Breast Cancer: A Case Report and Literature Review

Table 1. Case reports of drug-induced macular edema caused by taxane

\begin{tabular}{|c|c|c|c|c|c|c|c|}
\hline $\begin{array}{l}\text { Case } \\
\text { (first author [ref.]) }\end{array}$ & $\begin{array}{l}\text { Age, } \\
\text { years }\end{array}$ & $\begin{array}{l}\text { Affected } \\
\text { side }\end{array}$ & Symptom & Treatment & $\begin{array}{l}\text { Treatment time } \\
\text { to recovery }\end{array}$ & $\begin{array}{l}\text { Causing } \\
\text { agent }\end{array}$ & Bevacizumab \\
\hline Joshi [3] & 63 & bilateral & $\begin{array}{l}\text { decreased } \\
\text { vision }\end{array}$ & cessation & 6 weeks & PTX & no \\
\hline Ham [13] & 57 & bilateral & $\begin{array}{l}\text { decreased } \\
\text { vision }\end{array}$ & $\begin{array}{l}\text { cessation, } \\
\text { intravitreal } \\
\text { bevacizumab }\end{array}$ & 6 weeks & PTX & yes \\
\hline Kuznetcova [9] & 64 & bilateral & $\begin{array}{l}\text { decreased } \\
\text { vision }\end{array}$ & cessation & 4 weeks & PTX & yes \\
\hline $\begin{array}{l}\text { Murphy [7] } \\
\text { first case }\end{array}$ & 65 & bilateral & $\begin{array}{l}\text { decreased } \\
\text { vision }\end{array}$ & $\begin{array}{l}\text { cessation, NSAIDs, } \\
\text { topical steroids }\end{array}$ & 3 weeks & nab-PTX & yes \\
\hline $\begin{array}{l}\text { Murphy [7] } \\
\text { second case }\end{array}$ & 58 & bilateral & $\begin{array}{l}\text { decreased } \\
\text { vision }\end{array}$ & cessation & 3 weeks & nab-PTX & yes \\
\hline Matsuoka [16] & 39 & bilateral & $\begin{array}{l}\text { decreased } \\
\text { vision }\end{array}$ & STTA, cessation & $\begin{array}{l}11 \text { months, not } \\
\text { fully recovered }\end{array}$ & nab-PTX & no \\
\hline Teitelbaum [4] & 53 & bilateral & $\begin{array}{l}\text { blurred } \\
\text { vision }\end{array}$ & cessation & 6 weeks & DTX & no \\
\hline Telander [5] & 60 & bilateral & $\begin{array}{l}\text { decreased } \\
\text { vision }\end{array}$ & $\begin{array}{l}\text { cessation, } \\
\text { acetazolamide }\end{array}$ & 16 weeks & DTX & no \\
\hline Enzsoly [6] & 45 & bilateral & $\begin{array}{l}\text { decreased } \\
\text { vision }\end{array}$ & $\begin{array}{l}\text { cessation, topical } \\
\text { nepafenac }\end{array}$ & 5 weeks & DTX & no \\
\hline
\end{tabular}

PTX, paclitaxel; nab-PTX, nanoparticle albumin-bound paclitaxel; DTX, docetaxel; NSAID, nonsteroidal anti-inflammatory drug; STTA, subTenon triamcinolone acetonide injection. 